\title{
Reducing the Decarbonisation Cost Burden for EU Energy-Intensive Industries
}

\author{
Panagiotis Fragkos*(D), Kostas Fragkiadakis $(D)$ and Leonidas Paroussos \\ E3Modelling S.A., Panormou 70-72, PO 11523 Athens, Greece; fragkiadakis@e3modelling.com (K.F.); \\ paroussos@e3modelling.com (L.P.) \\ * Correspondence: fragkos@e3modelling.com
}

\begin{abstract}
Carbon leakage features prominently in the climate policy debate in economies implementing climate policies, especially in the EU. The imposition of carbon pricing impacts negatively the competitiveness of energy-intensive industries, inducing their relocation to countries with weaker environmental regulation. Unilateral climate policy may complement domestic emissions pricing with border carbon adjustment to reduce leakage and protect the competitiveness of domestic manufacturing. Here, we use an enhanced version of GEM-E3-FIT model to assess the macro-economic impacts when the EU unilaterally implements the EU Green Deal goals, leading to a leakage of $25 \%$ over 2020-2050. The size and composition, in terms of GHG and energy intensities, of the countries undertaking emission reductions matter for carbon leakage, which is significantly reduced when China joins the mitigation effort, as a result of its large market size and the high carbon intensity of its production. Chemicals and metals face the stronger risks for relocation to non-abating countries. The Border Carbon Adjustment can largely reduce leakage and the negative activity impacts on energy-intensive and trade-exposed industries of regulating countries, by shifting the emission reduction to non-abating countries through implicit changes in product prices.
\end{abstract}

Keywords: unilateral climate policy; GEM-E3-FIT; carbon leakage; industrial relocation; border carbon adjustment

Citation: Fragkos, P.; Fragkiadakis,

K.; Paroussos, L. Reducing the Decarbonisation Cost Burden for EU Energy-Intensive Industries. Energies 2021, 14, 236. https://doi.org/ 10.3390/en14010236

Received: 7 December 2020 Accepted: 31 December 2020 Published: 5 January 2021

Publisher's Note: MDPI stays neutral with regard to jurisdictional clai$\mathrm{ms}$ in published maps and institutional affiliations.

Copyright: $\odot 2021$ by the authors. Licensee MDPI, Basel, Switzerland. This article is an open access article distributed under the terms and conditions of the Creative Commons Attribution (CC BY) license (https:// creativecommons.org/licenses/by/ $4.0 /)$.

\section{Introduction}

Climate change is challenging for public policymakers, as the global nature of greenhouse gas (GHG) emissions increases the difficulty of implementing unilateral emission reduction actions as the country taking climate action bears most of the mitigation costs. As a global agreement on ambitious emission reduction seems unlikely and current pledges are not sufficient to meet Paris goals [1], individual countries implement unilateral climate policies hoping that other regions will adopt similar policies [2]. Unilateral action forgoes cost savings from "where-flexibility" [3], as the cheapest mitigation options across regions and sectors are not the first to be explored. That the unilateral climate policies lead to differential carbon prices across countries indicates an unexploited potential for cost savings. The application of unilateral carbon pricing results in structural adjustment of domestic production and consumption but also affects its competitiveness in international markets through changes in relative costs and trade patterns between countries. In this context, the cost-efficiency of climate policies is negatively impacted carbon leakage, i.e., the relocation of emissions to regions with weaker environmental regulation. Leakage occurs via two interlinked channels: (i) the energy channel, through adjustments in international energy prices, and (ii) the industrial competitiveness channel [4]. In the energy channel, reduced fossil fuel consumption in carbon abating countries depresses global prices for oil, gas and coal, which triggers increased fossil fuel consumption and emissions in non-abating countries. The competitiveness channel is triggered by increased production costs of energy-intensive and trade-exposed (EITE) industries in regulating countries relative to international competitors, resulting in industrial relocation to non-regulating countries. 
The socio-economic implications of unilateral climate policies are commonly analyzed with computable general equilibrium (CGE) models, which complement theoretical analysis as they allow researchers to conduct quantitative experiments in the form of scenarios exploring the impacts of specific policies [5]. National authorities and policymakers in the climate field place a high focus on domestic economy and employment effects, while the reaction of other countries is highly uncertain. These economic impacts are related to "loss of competitiveness" triggered by changes in output, export volumes and terms of trade, which may lead to delayed or weakened climate policies [5].

In the EU climate policy debate, industrial competitiveness is a key issue. Recently, the EU Green Deal [6] acknowledged that European ambitious climate policies may weaken the competitiveness of energy-intensive industries leading to relocation of their activities to countries with weaker climate ambition. In case of differentiated climate policy efforts across regions, the European Commission (EC) proposes a Border Carbon Adjustment (BCA) mechanism, for selected sectors, to ensure that the price of imported products reflects their carbon content. The BCA mechanism imposes a tax on emissions embodied in imported products to the EU in order to level the playing field between domestic and imported products with respect to carbon costs. With the right design, the BCA could prevent carbon leakage, incentivize foreign producers to shift toward lower emission technologies, and exert pressure on trade partners to strengthen their climate action. The BCA should comply with World Trade Organization rules and other international obligations of the EU. While BCA improves the global cost-efficiency of unilateral climate policies [7], it may cause adverse distributional impacts, as it may shift the economic burden of emission abatement from regulating to non-regulating countries [8], which may trigger increased international cooperation, but can also lead to detrimental trade conflicts, through retaliation measures.

The current study offers new insights on the risk of carbon leakage and industrial relocation in case of asymmetric climate policies (i.e., when climate policy measures have different ambition across countries) and provides an improved understanding of the sectoral and regional structure of leakage, as well as policy measures to mitigate the adverse impacts on industrial competitiveness. The paper goes beyond existing literature by: (1) assessing for the first time the competitiveness impacts of the ambitious EU Green Deal targets towards climate neutrality by mid-century, (2) using an advanced version of the leading GEM-E3-FIT model with an enhanced representation of energy system and technologies required for net zero transition, (3) exploring the impacts of first-mover coalitions conceptualising the most recent climate policy announcements of EU and China aiming to achieve carbon neutrality by mid-century, thus ensuring high policy relevance of the analysis and (4) assessing the cost-effectiveness of BCA mechanism in preventing carbon leakage and supporting the European EITE industries, as suggested by the EU Green Deal.

The study proceeds as follows. Section 2 presents the industrial and climate policy landscape in the EU, while Section 3 includes the study design and methodological approach. Section 4 presents the results of the model-based assessment on carbon leakage. Section 5 concludes the paper.

\section{European Policy Landscape}

\subsection{The European Industrial Context}

The industrial sector is a backbone of the European economy as it accounts for $68 \%$ of Europe's exports and about $18 \%$ of total EU value added with manufacturing activities providing about 32 million jobs in the EU in 2018. The EC acknowledges that the EU industry is undergoing a deep transformation, based on the uptake of new technologies, changing conditions in international markets, stronger energy and resource efficiency, new business models, bundling of manufacturing activities with services [9]. EC plans focus on boosting activity in key industry sectors, including steel, paper, construction, green technologies, renewable energies and maritime shipping [9]. The COVID-19 pandemic and 
the imposed restrictions heavily impacted the global and EU manufacturing activities and disrupted the international value chains, with potential for long-term economic impacts related to localisation of production, remote working and changes in travel patterns.

Several major trends shape the future development of the EU industrial sector, as European industries face growing international competition in traditional energy-intensive products like steel, cement and chemicals. European businesses will also encounter strong competition for new products entering the market, e.g., electric vehicles, renewable technologies, batteries, contributing to the UN Sustainable Development Goals [8]. Industrial policies and technological development are still too weakly coordinated, with large barriers of moving from R\&D to market phase in most countries. The increasing carbon taxation would pose additional challenges for the European carbon- and material-intensive industries, which face increased risks of activity relocation to non-abating countries. The EU industrial policy should appropriately integrate considerations for key megatrends shaping future developments, including automation, digitization, globalisation, new business models and climate policies. Increasing globalisation would increase the competition of EU industries with their international competitors, as EU competitiveness in traditional industries depends crucially on labour costs and environmental regulation; however, increased innovation and R\&D may increase European competitiveness in all high-tech branches. The increasingly globalised market requires the long-term transformation of the EU industry towards an "energy and resource efficiency" paradigm based on circular economy, uptake of low-carbon technologies (e.g., green hydrogen, electrification) and novel manufacturing principles, e.g., Industry 4.0 and ICT-based management. EU industrial policies should be aligned with overall economic, financing and education policies aiming to foster industrial competitiveness, through providing friendlier framework conditions for entrepreneurial activities and business venture formation, supporting firms' innovative capacities and developing better human resource reallocation and skills growth.

Energy-intensive industries have high capital and energy intensities, as the processing of raw materials requires high-temperature chemical conversions. Such processes have high efficiency potential for economies of scale, which results in large-scale manufacturing plants with high upfront costs. The recovery of high capital costs in highly volatile markets depends on high utilisation of manufacturing capacities, implying that plants may keep operating as long as product prices are higher than variable production costs, while the profitability of such plants is high during periods of high prices [10]. The high scale and capital intensity of energy-intensive activities pose barriers to market entry with new entrants often having to cooperate with or be absorbed by major established players.

\subsection{European Policies on Carbon Leakage}

Carbon leakage has been closely related with competitiveness in international markets and unilateral climate policies [11,12]. If a country or a group of countries adopt ambitious climate policies, while the rest of the world does not follow suit, energy-intensive manufacturing activities may relocate to non-abating regions aiming to minimise their carbon-related production costs. This issue is central in EU climate policy debate, especially as the EU Green Deal suggested the Border Carbon Adjustment (BCA) as a measure to minimise the risk of industrial relocation of European energy-intensive activities. It should be noted that there are limited indications that existing EU carbon pricing has led to carbon leakage [13], as the current EU ETS price remains at low levels and free allowances are given to energy-intensive and trade-exposed industries. However, the anticipated increase in EU ETS prices, due to the strengthening of GHG reduction targets, combined with changes in anti-leakage legislation would increase the risk of carbon leakage in the coming decades [9].

The transfer of manufacturing activities to countries with weaker environmental regulations due to cost increases related to carbon pricing is defined as carbon leakage, which results in increased emissions in non-regulating countries, thus reducing the climate policy effectiveness. Industries where energy costs account for a high share of their production 
costs face high risk of leakage. The EU ETS supports the competitiveness of industrial installations considered to be at significant risk of leakage by giving them a high share of free allowances. Phase 3 of EU ETS uses the below criteria to identify if a sector faces high risk of leakage:

- ETS pricing would increase its production cost, calculated as a share of gross value added, by at least $5 \%$; and

- $\quad$ its trade intensity with countries outside the $\mathrm{EU}$ is above $10 \%$.

- The value of at least one of the above indicators is higher than $30 \%$

The amount of free allocation for each ETS installation is estimated based on its production quantity multiplied with the benchmark carbon intensity value for the specific product, which derives from the most efficient installations. Sectors facing high leakage risk (e.g., metals, chemicals, non-metallic minerals) receive $100 \%$ free allocation of emission allowances. However, the free allocation to other industrial sectors is gradually reduced from $80 \%$ in 2013 to $30 \%$ in 2020. In phase 4 of EU ETS, free allocation will focus on sectors facing the highest leakage risks. Figure 1 presents the carbon leakage exposure for EU industrial sectors as a function of their GHG emission intensity and trade openness. Basic metals, chemicals, non-metallic minerals, petroleum products, paper and pulp are the industries more exposed to carbon leakage, while sectors like motor vehicles, electrical equipment and electronic products face lower relocation risks due to their significantly lower GHG intensity (Figure 1).
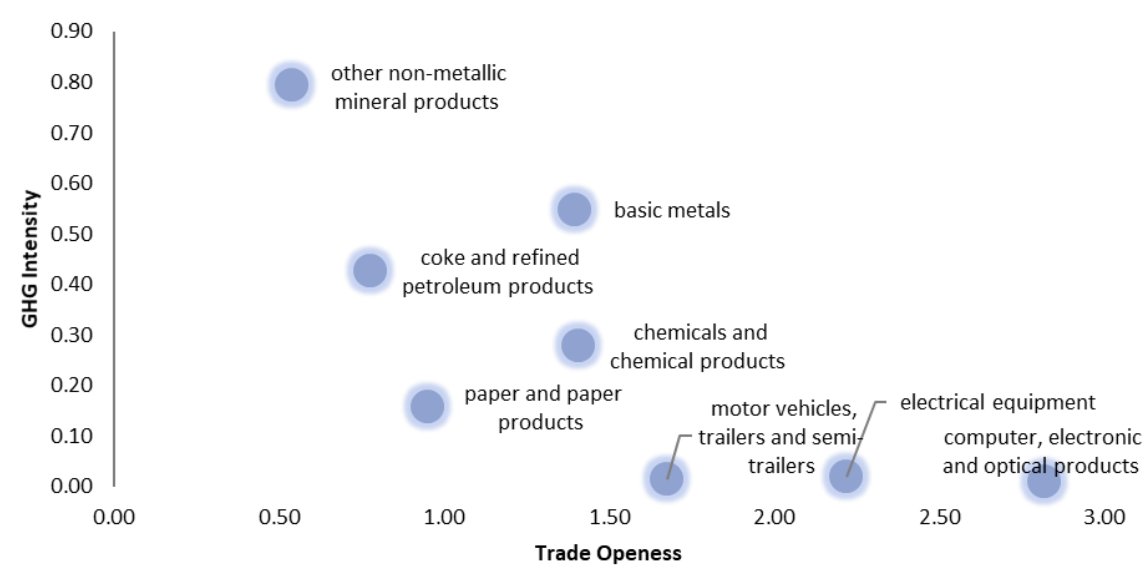

Figure 1. Carbon leakage exposure of EU sectors as a function of trade openness and GHG intensity.

The carbon leakage list of the European Commission includes those sectors with particularly high exposure to leakage, in which the contribution of energy to total production costs is about five times higher than in other industries [4]. Energy-intensive manufacturing accounts for about $7 \%$ of global GDP, but consumes $60 \%$ of global energy used by industries, mostly in the EU, USA, China, Korea and Russia. The European production of metals and chemicals is more exposed to foreign competition relative to other industries, due to their high trade intensity with non-EU countries. Non-energy intensive products (e.g., pharmaceuticals) do not face such high leakage risks as carbon pricing has limited impacts on their costs. Carbon leakage also depends on the easiness of industrial relocation (captured by transportation costs) and the degree of vertical integration of industrial activities (e.g., strong relation between car manufacturing and metals). The EU's main trading partners are China and the USA, followed by India, Russia, Turkey and Japan. Trade partners with good access and geographical proximity to the EU market and weak climate policies are the primary candidates for relocation of manufacturing activities.

Figure 2 shows that energy costs as a share of total production costs have declined from 2010 to 2017 for EU manufacturing sectors, with the largest reduction observed in the Pulp and Paper sector, in which costs fell from $11.4 \%$ in 2010 to a $6.7 \%$ share in 2017. 


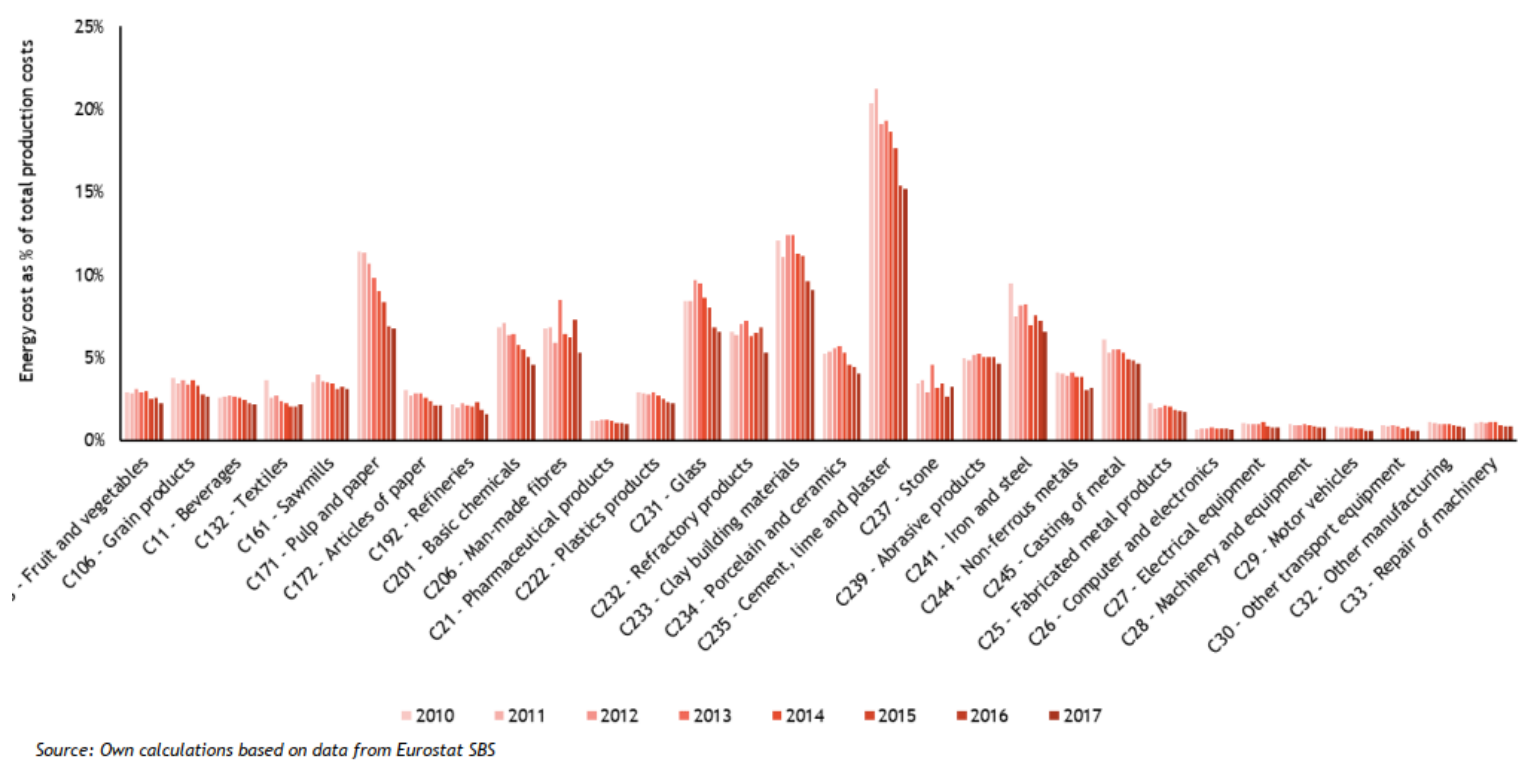

Figure 2. Energy costs as a share of production costs for EU manufacturing sectors over 2010-2017, source: [14].

Energy costs for EU manufacturing sectors typically account for 1-10\% of total production costs, while costs exceed $10 \%$ for several sectors, including Cement, lime and plaster, Building materials, Glass, Pulp and paper. These sectors are most sensitive to changes in energy prices and carbon taxation. Among less energy intensive manufacturing sectors, energy costs typically constitute $0.5-3 \%$ of their production costs and are therefore a relatively small cost component for businesses in sectors like Computer and electronics, Machinery and equipment, Transport equipment and Motor vehicles. Energy cost shares have fallen across all manufacturing sectors over 2010-2017, but even more steeply after 2014 due to reduced energy consumption and lower prices for energy products. The EU has energy cost shares comparable to those of most international trade partners, although there are large differences across sectors and regions [14]. For example, the EU has a relatively high energy cost share in Iron and steel and Non-ferrous metals, but a low energy cost share in Refineries and Basic chemicals.

\subsection{Policy Measures to Protect Domestic Industries}

Several policy options to reduce the adverse impacts of high carbon pricing on industrial competitiveness have been proposed. These can be classified in three categories as in [12]:

Policy instruments adjusting the carbon costs at the border of the jurisdiction implementing the carbon pricing scheme. The EU Green Deal suggests to adopt a BCA mechanism in order to protect the competitiveness of the most venerable EU industries. This instrument aims to equalize the carbon costs on imports and exports in the jurisdiction implementing the carbon price through imposing the same carbon price on imports from non-regulated countries and rebating the carbon costs to exports to non-regulated countries. This can also take the form of an EU-wide horizontal tax on carbon content, through a carbon price levied on consumption of goods regardless of their origin. While the measure is effective in reducing carbon leakage of EITE industries, it may lead to negative socio-economic outcomes in EU countries.

Adjusting carbon costs upwards for non-domestic firms: These measures aim at increasing the carbon costs of firms outside the jurisdiction implementing the climate policy. This may take the form of sectoral agreements aiming to extend the participation of industries in climate action by offering options such as technology transfers, research and development collaboration, etc. However, a revision of existing multilateral trade rules with major trade partners is difficult, in particular agreeing on cutting industrial subsidies. 
Policy measures to adjust carbon costs downwards for domestic firms by reducing their carbon-related costs but maintaining a marginal abatement incentive equivalent to that if such measures are not introduced. For example, free allocation of tradable permits, e.g., under an Emission Trading System like the EU ETS, can relieve industries from buying the emission permit but maintains the incentive to abate emissions. Carbon tax revenues can also be used to support investment (e.g., in low-carbon innovation) that will reduce the cost of low-carbon and efficient technologies.

Environmental tax reforms aim to shift taxation towards polluting activities, while output-based rebates return the revenues generated by a carbon tax to industries in proportion to their output. Carbon Border Adjustment has recently received increasing focus in policy debates after the EC suggestion to introduce BCA as part of the EU Green Deal. Given the high policy relevance of BCA and the drawbacks of other anti-leakage options (especially with regard to their non-compliance with WTO trade rules), the paper focuses on the assessment of BCA as a policy measure to reduce the cost burden on EITE sectors, by imposing the EU carbon price on imported products from non-regulating countries.

\section{Methodology}

\subsection{The GEM-E3-FIT Modelling Framework}

GEM-E3-FIT is an advanced and detailed applied computable general equilibrium (CGE) model, simultaneously representing 46 countries/regions, including all EU-28 countries individually and the largest economies globally (USA, Japan, Canada, Brazil, China, India, South Korea, Indonesia, Saudi Arabia, Russian federation, South Africa and others). GEM-E3-FIT covers the interactions between the economy, the energy system and the environment. It is a comprehensive model of the economy, covering the complex interlinkages between productive sectors, consumption, price formation of commodities, labour and capital, bilateral trade and investment dynamics. The model is dynamic, recursive over time, driven by accumulation of capital and equipment. The economic agents are assumed to exhibit optimising behaviour while market-derived prices are adjusted to clear all markets. The model features alternative market regimes, discrete representation of power producing technologies, equilibrium unemployment, energy efficiency standards and carbon pricing. GEM-E3-FIT formulates production technologies in an endogenous manner allowing for price-driven derivation of intermediate consumption and the services from capital and labour. The model can quantify the macroeconomic, trade, employment and distributional impacts of environmental and energy policies, both in the short and long term.

For alternative scenarios, GEM-E3-FIT provides for 51 countries: dynamic projections of national accounts; full Input-Output tables; distribution of income and transfers by agent; employment by economic activity and by skill; capital and investment by sector; $\mathrm{CO}_{2}$ and GHG emissions by sector and fuel; consumption matrix by product and investment matrix by ownership branch; full bilateral trade matrices among countries and sectors; energy demand and supply by sector and fuel, energy efficiency investment and power generation mix. GEM-E3-FIT goes beyond a conventional CGE modelling approach, as it incorporates: a detailed representation of the financial sector, endogenous growth through learning-by-doing and R\&D for low-carbon technologies [15], five labour skill levels and comprehensive energy system representation. GEM-E3-FIT has been extensively used for energy and climate policy assessment $[16,17]$.

In GEM-E3-FIT, all regions and sectors are linked through endogenous bilateral trade flows. Total demand of each sector is optimally allocated between domestic and imported goods, under the hypothesis that they are imperfect substitutes (Armington assumption [18]). The supply mix is represented as a multi-level nested constant elasticity of substitution function: at the upper level, firms decide on the optimal mix between domestically produced and imported goods; at the next level the demand for imports is split by country of origin. Bilateral trade transactions are endogenous in GEM-E3-FIT and depend on relative production costs, transportation costs and consumer preferences, as 
captured by national account statistics on trade. The mathematical formulation adopted in GEM-E3-FIT is described in [4] and model details are presented in Appendix A. Table 1 includes the upper-level Armington elasticity values used in GEM-E3-FIT ( $\sigma x)$ and the elasticity values driving the decision on imports by origin $(\sigma \mathrm{m})$, which differ among sectors, largely reflecting the degree of product homogeneity. The values of Armington elasticities are derived from the GTAP 10 database.

Table 1. Armington elasticities in GEM-E3-FIT sectors.

\begin{tabular}{cccccc}
\hline & $\boldsymbol{\sigma x}$ & $\boldsymbol{\sigma m}$ & & $\boldsymbol{\sigma x}$ & $\boldsymbol{\sigma m}$ \\
\hline Transport & 1.90 & 3.80 & Coal & 3.05 & 6.10 \\
Construction & 1.90 & 3.80 & Consumer Goods & 3.21 & 6.43 \\
Non Market Services & 1.90 & 3.80 & Chemical Products & 3.30 & 6.60 \\
Market Services & 2.03 & 4.06 & Transport equipment & 3.55 & 7.10 \\
Oil products & 2.10 & 4.20 & Electric Vehicles & 3.55 & 7.10 \\
Gas & 2.80 & 5.60 & Non-ferrous metals & 3.98 & 7.95 \\
Power Supply & 2.80 & 5.60 & Equipment goods & 4.05 & 8.10 \\
Ferrous metals & 2.95 & 5.90 & Batteries & 4.05 & 8.10 \\
Paper Products & 2.95 & 5.90 & Electronic Goods & 4.08 & 8.15 \\
Agriculture & 3.03 & 6.07 & Crude Oil & 5.20 & 10.40 \\
\hline
\end{tabular}

\subsection{Study and Scenario Design}

Alternative policy scenarios are modelled with GEM-E3-FIT to assess the macroeconomic and industrial implications of unilateral climate policy and evaluate possible measures to reduce the cost burden on EITE industries.

The Reference scenario represents a benchmark macroeconomic projection based on scientific expertise on growth patterns, technical progress, labour productivity and climate policies. The key macroeconomic and international energy price assumptions follow [19], while socio-economic assumptions for the EU are based on the Ageing Report [20]. This scenario assumes that already legislated climate policies, including Nationally Determined Contributions (NDCs), are implemented by 2030 (Table 2). After 2030, no additional emission reduction efforts are assumed. In modelling terms, this means that the carbon prices resulting from NDC targets in 2030 are kept constant until 2050, representing a lack of ambition in the international climate policy landscape. The costs of power generation technologies follow [21], while technology progress is included for low-carbon technologies.

Table 2. Nationally Determined Contributions (NDC) emission targets included in the Reference scenario.

\begin{tabular}{crc}
\hline Country & NDC Emission Targets & Energy-Related NDC Targets in 2030 \\
\hline EU & $-40 \%$ GHG in 2030 relative to 1990 & $30 \%$ RES in gross final demand \\
China & $-60 \%(-65 \%) \mathrm{CO}_{2}$ intensity in 2030 rel. 2005 & $20 \%$ Non-fossil in primary energy \\
India & $-33 \%(-35 \%) \mathrm{CO}_{2}$ intensity from 2005 & $40 \%$ Non-fossil in power capacity \\
USA & $-26 \%(-28 \%)$ GHG in 2025 from 2005 & electricity in 2030 \\
Japan & $-26 \%$ GHGs in 2030 from 2013 & \\
Brazil & $-43 \%$ GHGs in 2030 from 2005 & \\
Russia & $25-30 \%$ below 1990 levels by 2030 & \\
S. Korea & $37 \%$ below Business as Usual by 2030 & \\
S. Africa & Peak GHG emissions in 2025 and plateau & \\
\hline
\end{tabular}

The 2DEG scenario is compatible with the $2{ }^{\circ} \mathrm{C}$ goal of the Paris Agreement, and as in [22], the global $\mathrm{CO}_{2}$ budget of $1000 \mathrm{GtCO}_{2}$ by 2050 is used as proxy for the temperature target (Table 3). To ensure that the temperature increase relative to pre-industrial levels will stay below $2{ }^{\circ} \mathrm{C}$, a carbon price is implemented in all regions and sectors over 2025-2050. The global carbon price is projected to increase from $75 \$ / \mathrm{tnCO}_{2}$ in 2030 to about $345 \$ / \mathrm{tnCO}_{2}$ in 2050 reflecting the increasing difficulty to reduce emission in hard-to-abate sectors including industries and freight transport. The scenario assumes equalization 
of marginal abatement costs across regions (i.e., common carbon price), leading to the cost-optimal achievement of the global constraint. As model results depend on the adopted carbon revenue recycling scheme, we assume that carbon revenues are recycled through the public budget.

Table 3. Scenario description.

\begin{tabular}{|c|c|c|c|}
\hline & Scenario Description & EU Climate Target & Non-EU Climate Targets \\
\hline REF & Reference scenario & Meets the EU NDC & $\begin{array}{c}\text { All countries meet NDCs in 2030, } \\
\text { no increase in policy ambition } \\
\text { after } 2030\end{array}$ \\
\hline 2DEG & $\begin{array}{l}\text { Decarbonisation to } 2{ }^{\circ} \mathrm{C} \text { with all } \\
\text { options available }\end{array}$ & \multicolumn{2}{|c|}{$\begin{array}{l}\text { All countries adopt ambitious climate policies/universal carbon pricing to } \\
\text { meet the } 2{ }^{\circ} \mathrm{C} \text { temperature target }\end{array}$} \\
\hline EUGD_Alone & $\begin{array}{l}\text { EU meets the EU Green Deal } \\
\text { Targets by } 2030 \text { and } 2050\end{array}$ & $\begin{array}{l}\text { EU achieves 55/90\% reduction in } \\
\text { 2030/2050 from } 1990\end{array}$ & $\begin{array}{l}\text { Non-EU countries meet their } \\
\text { NDCs in 2030, policy ambition } \\
\text { does not increase beyond } 2030\end{array}$ \\
\hline EUGD_BCA & $\begin{array}{l}\text { Green Deal Targets are met, BCA } \\
\text { is implemented on EU imports }\end{array}$ & $\begin{array}{l}\text { EU achieves 55/90\% reduction in } \\
\text { 2030/2050 from } 1990\end{array}$ & $\begin{array}{l}\text { Non-EU countries meet their } \\
\text { NDCs in 2030, policy ambition } \\
\text { does not increase beyond } 2030\end{array}$ \\
\hline EUGD_BCA_REC & $\begin{array}{c}\text { As EUGD_BCA but BCA } \\
\text { revenues are used to reduce social } \\
\text { security contributions }\end{array}$ & $\begin{array}{l}\text { EU achieves 55/90\% reduction in } \\
\text { 2030/2050 from } 1990\end{array}$ & $\begin{array}{l}\text { Non-EU countries meet their } \\
\text { NDCs in 2030, policy ambition } \\
\text { does not increase beyond } 2030\end{array}$ \\
\hline EUGD-CHN & $\begin{array}{c}\text { EU and China adopt ambitious } \\
\text { climate policies }\end{array}$ & $\begin{array}{l}\text { EU achieves 55/90\% reduction in } \\
\text { 2030/2050 from } 1990\end{array}$ & $\begin{array}{l}\text { Countries do not intensify policy } \\
\text { ambition beyond 2030; China } \\
\text { develops along a 2DEG trajectory }\end{array}$ \\
\hline
\end{tabular}

In the "EUGD-Alone" scenario, the EU unilaterally adopts ambitious policies to achieve the EU Green Deal targets of 55\% emission reduction in 2030 from 1990 levels and the transition to climate neutrality by mid-century. As the EU Green Deal does not separately set a target for ETS and non-ETS, an EU-wide uniform carbon price is used from 2025 onwards. Energy system restructuring is mostly induced by high carbon pricing, while other instruments are also used, including ambitious technology standards, subsidies for buildings' insulation, lower risks for clean energy investment, electrification of energy services, subsidies for low-carbon innovation and uptake of disruptive mitigation options required for climate neutrality (e.g., Carbon Capture Use and Storage, green hydrogen, production of clean synthetic fuels from RES-based electricity). In contrast, non-EU countries follow their Reference climate policies.

As the EU intends to unilaterally adopt ambitious climate measures, the BCA instrument can complement domestic carbon pricing. The "EUGD-BCA" scenario explores the socio-economic and industrial implications of implementing an EU-wide BCA mechanism on imports building on "EUGD-Alone" scenario assumptions, but additionally assuming that the BCA is aligned with the EU ETS carbon pricing and applies to products subject to the ETS (e.g., energy-intensive industries). The BCA is implemented as a financial instrument (e.g., as a tax), based on the difference between EU ETS benchmarks and the carbon profiles of products originating from trading partners. Imported goods from nonEU regions are taxed according to their carbon content, which is calculated accounting for the direct GHG emissions. Tariff rates are differentiated by country, based on carbon flow data to determine country-specific coefficients. In particular, the BCA revenues of EU countries from non-EU regions for each sector $s$ and year $t$ can be calculated as follows:

$$
B C A_{s, e u, n o n e u, t}=I M P_{s, e u, n o n e u, t} \cdot C I_{s, \text { noneu }, t} \cdot D I F F_{s, e u, t}
$$

where $I M P_{s, e u, n o n e u, t}$ is the value of EU imports from non-EU countries.

CI represents the Carbon intensity of non-EU countries, calculated as the Scope 1 emissions divided by the value of production of sector $s$ at year $t$.

DIFF: The EU carbon price difference between the EUGD-BCA and Reference scenario.

The BCA revenues are directed to the public budget of the regulating country. Export rebates can be considered as a subsidy under WTO's Agreement on Subsidies and Countervailing Measures [23] and are thus difficult to implement. The scenario assumes 
no retaliation measures from major trade partners. A variant of the BCA scenario assumes that BCA revenues are used to reduce social security contributions ("EUGD-BCA-REC" scenario). To explore if leakage depends on the size of regulating regions, we develop the "EUGDCHN" scenario, where the EU and China jointly pursue an ambitious emission reduction effort. This scenario reflects the recent policy announcements by the EU and China, aiming for a carbon-neutral transition by 2050 and 2060 respectively. In particular, the joint emission reduction effort of the EU and China is equal to the aggregate reductions achieved by the EU (in the EUGD-Alone scenario) and China (in the 2DEG scenario). Decarbonisation is triggered by the imposition of a uniform carbon price, which constantly increases from 2025 onwards to achieve the ambitious EU-China emission reduction target. Other countries follow the same climate policies as in the Reference scenario.

The study focuses on industrial competitiveness impacts of unilateral climate policies and thus hydrocarbon supply is assumed to be elastic. Many reasons support the high elasticity of fossil fuel supply, as summarised in [5], including the small fraction of coal traded globally and the high oligopolistic rents of oil and gas whose prices are much higher than their production costs. This implies that changes in fossil fuel demand produce minor changes in international fossil fuel prices and limited leakage through the energy channel.

\section{Scenario Results}

The section explores the socio-economic and industrial impacts of asymmetric climate policies and possible protective measures for EITE industries.

\subsection{Impacts of Unilateral Ambitious European Climate Policies}

The EC recently proposed a new plan to increase its GHG emission reduction target for 2030, accompanied with the long-term climate neutrality goal by 2050 . This proposal forms the basis of the EUGD-Alone Scenario, which meets the ambitious GHG reduction targets of 55\% in 2030 and 90\% in 2050 relative to 1990 levels. As the EU Green Deal does not set sectoral targets, an EU-wide carbon price is used, which reaches $75 \$ / \mathrm{tnCO}$ in 2030 and $590 \$ / \mathrm{tnCO}_{2}$ in 2050 indicating the increasing marginal abatement effort and difficulty in fully decarbonizing the European energy system, especially in hard-to-abate sectors with limited mitigation options, including energy-intensive industries and freight transport. The high carbon price drives a large-scale reduction in GHG emissions, which decline to about $575 \mathrm{Mt} \mathrm{CO}$ in 2050, compared to $2350 \mathrm{Mt} \mathrm{CO}_{2}$ in the Reference scenario, i.e., a reduction of $75 \%$. This reduction is mostly driven by energy system decarbonisation, with extensive emission reductions projected in all sectors. Industrial $\mathrm{CO}_{2}$ emissions decline significantly from Reference levels, as European industries are decarbonised through large-scale efficiency improvements, electrification of industrial processes and fuel switch towards energy carriers with low carbon intensity, e.g., biomass and green hydrogen, while domestic industrial activity also declines, as a part of energy-intensive manufacturing is relocated to countries without carbon pricing.

Figure 3 shows that all sectors and GHGs contribute to the ambitious EU emission reduction effort, but energy-related $\mathrm{CO}_{2}$ emissions account for $73 \%$ of the overall mitigation effort, due to energy demand and supply restructuring. The European industrial sector accounts for about $25 \%$ of the overall EU mitigation effort relative to Reference, with large reduction of $\mathrm{CO}_{2}$ emissions both from energy combustion and industrial processes.

Energy system decarbonisation is a capital-intensive process characterized by the transition towards low-carbon technologies, which require high upfront investment costs, but result in reduced operation and fuel costs in the longer term. A strict financial closure is adopted in the CGE modelling framework where investments are constrained by available savings and any additional investment plan needs to be financed by reallocating existing capital resources, leading to crowding-out of productive investment in other sectors. In this context, increased demand for low-carbon finance would increase the cost of capital with negative implications throughout the economy. The high carbon pricing increases the EU production costs of energy- and carbon-intensive processes, while the low-carbon 
technology costs decline due to their increased uptake (learning-by-doing). However, as non-EU countries do not intensify their policy ambition, the non-EU market demand for low-carbon technologies remains relatively small and thus the potential export benefits from a competitive EU low-carbon manufacturing are limited. In the EUGD-Alone Scenario, the driving factor for industrial relocation to non-regulating countries is the change in production costs of carbon-intensive sectors through higher carbon prices.

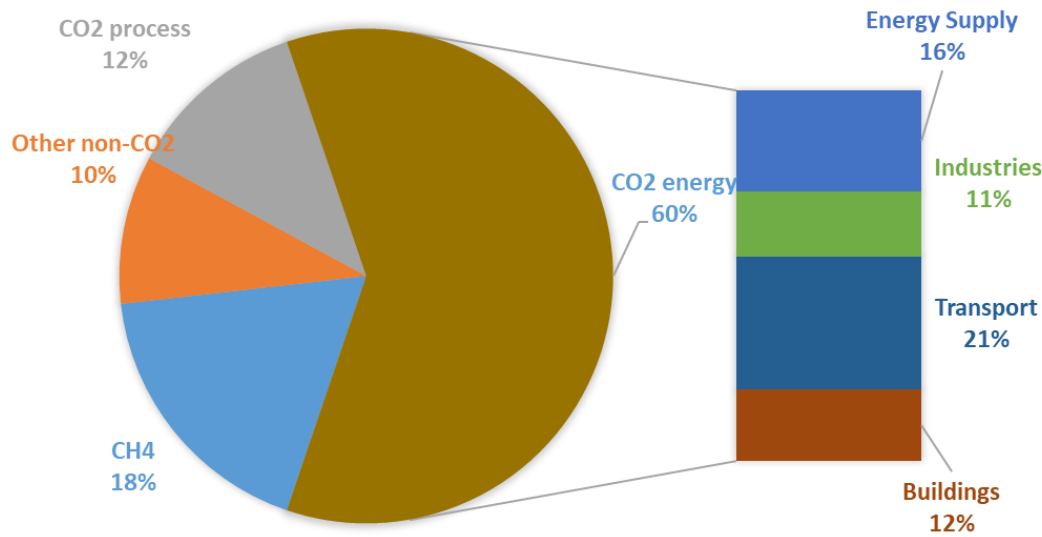

Figure 3. Distribution of the EU GHG mitigation effort by sector in the EUGD-Alone relative to the Reference scenario in 2050.

As the EU unilaterally adopts ambitious climate policies in the EUGD-Alone scenario, GHG emissions outside the EU increase as energy- and carbon-intensive industries are relocated to non-abating countries and domestically produced goods are substituted with imported goods. The cumulative carbon leakage is calculated as the ratio of increased emissions in non-abating countries over the amount of emission reductions in regulating countries compared to Reference scenario and is estimated at $24.6 \%$ with EU GHG emissions declining by about 24 Gt cumulatively over 2025-2050, while non-EU emissions increase by about $5.9 \mathrm{Gt}$ relative to Reference scenario. Leakage rate increases over time following the increase in carbon price differential between countries compared to Reference scenario. Most carbon leakage occurs in Russia, Rest of World, China, India and the United States which increase emissions in the EU-GD-Alone scenario (Figure 4). Low transportation costs to the EU market favour Russia and Turkey, while China and India have sufficient production capacities at low cost and relatively high energy and carbon intensities inducing a higher increase in emissions (hence, higher leakage). It should be noted that the industrial relocation to the different countries is not proportional to the changes in GHG emissions as each country is characterised by different GHG intensities (e.g., one tonne of steel produced in the USA emits lower GHG emissions than in India).

The sectoral distribution of carbon leakage is presented in Figure 5. Given their high carbon intensities and openness to trade ratios, the sectors that are most vulnerable to carbon leakage are Chemicals, Metals, Non-metallic minerals and Air transport. The importance of sectoral leakage changes over time as the energy system is gradually decarbonised. An interesting finding is that carbon leakage occurs also indirectly through electricityrelated emissions; the relocation of industrial activities to non-EU countries would lead to increased demand and production of electricity and thus higher carbon emissions in non-EU countries, especially as their power mix is still dominated by fossil fuels in the EUGD-Alone scenario. GHG emissions from refineries increase in most non-EU countries driven by the increased demand for oil products required to fuel industrial activities. However, in other countries, refinery emissions decline as the electrification of the EU energy services reduces the aggregate demand for refined oil products. 


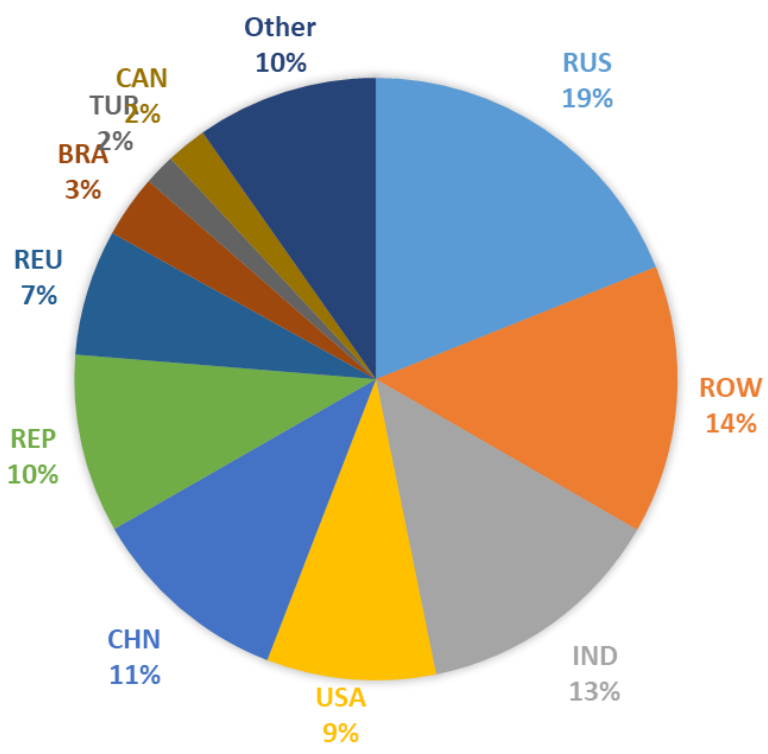

Figure 4. Regional decomposition of carbon leakage in EUGD-Alone over 2020-2050.

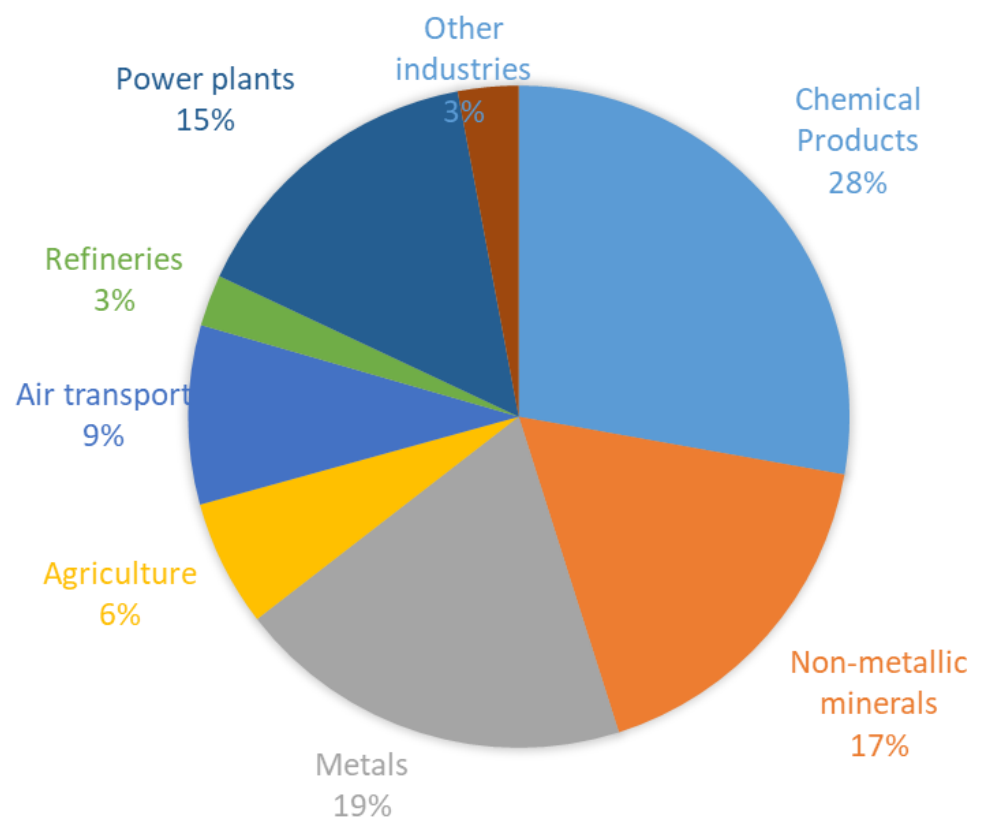

Figure 5. Sectoral decomposition of carbon leakage in EUGD-Alone over 2020-2050.

The model-based simulations show negative impact of high carbon pricing on economic activity, as higher costs for energy services increase production costs and depress demand, in the presence of crowding-out effects. The unilateral application of carbon pricing in an open economy weakens its international competitiveness leading to further decline in domestic activity, some parts of which are substituted by carbon-intensive production in non-EU countries emitting more GHGs. This reduced the effectiveness of unilateral climate policies through carbon leakage to non-regulating countries. The GEME3-FIT results confirm that the unilateral application of high carbon pricing would result in GDP and consumption losses in the EU compared to Reference scenario. The EU has a strong low-carbon innovation base and industrial know-how so as to build domestically a large part of the clean energy technologies [24], but the corresponding activity increase 
is not high enough to offset the depressing effects due to higher production costs and the relocation of industrial activity to non-abating countries.

GEM-E3-FIT results show that the cumulative EU GDP losses in the EUGD-Alone scenario over 2025-2050 are 1\% below reference scenario GDP. As the carbon price differential between the two scenarios increases over time, EU GDP losses follow the same trend (Figure 6). Non-regulating countries benefit from their increased competitiveness, but also face losses as demand for their products declines in the EU, which experiences depressive effects on domestic demand due to carbon pricing. Therefore, the scenario has very small impacts on GDP of non-regulating regions, while GDP declines at the global level relative to Reference levels due to carbon pricing application.

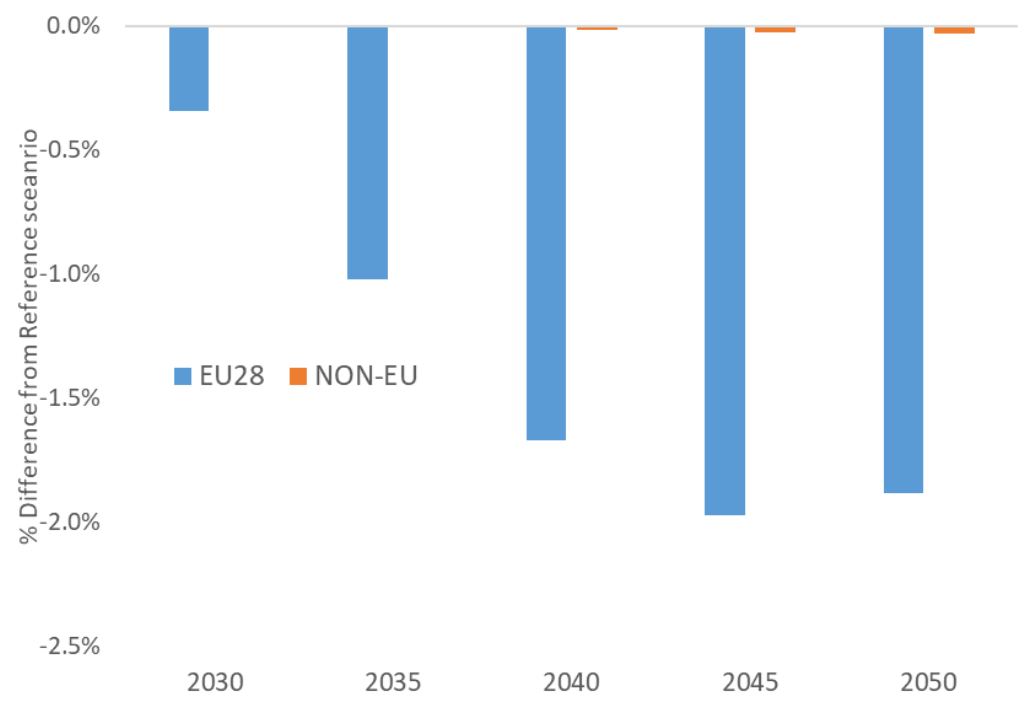

Figure 6. GDP implications of EUGD-Alone relative to Reference scenario.

In emission-abating countries, demand for energy-intensive products declines from Reference levels, because of increased production costs and despite their participation in building the low-carbon investment (e.g., metals contribute to wind turbine production). The reduction in domestic EU production of EITE industries is also driven by the worsening of their international competitiveness induced by unilateral application of carbon pricing. The degree of exposure of these industries to foreign trade is a critical factor influencing industrial relocation.

Figure 7 shows that the unilateral application of high carbon pricing impacts negatively the domestic EU industrial production. Energy system decarbonisation has profound negative impacts for the EU fossil fuel supply industries, which register a large activity reduction due to the reduced consumption of oil, coal and natural gas. A large activity decline is also projected for the domestic production of ferrous metals and chemicals (between $8-10 \%$ ), while the decline is lower in other industrial sectors, as non-metallic minerals and paper are less traded. Part of the decreased activity is relocated to non-EU countries that do not adopt climate policies. The amount of industrial production increased in non-regulating regions is lower than the reduced EU production, because energy-intensive products face lower global demand relative to Reference scenario, as they are replaced by products with low carbon intensity induced by ambitious EU climate policies (Table 4). The sectors producing metals and chemicals are more exposed to foreign competition and bear higher relocation impacts than cement (and other building materials) which have to be located close to consumption due to high transportation costs. 


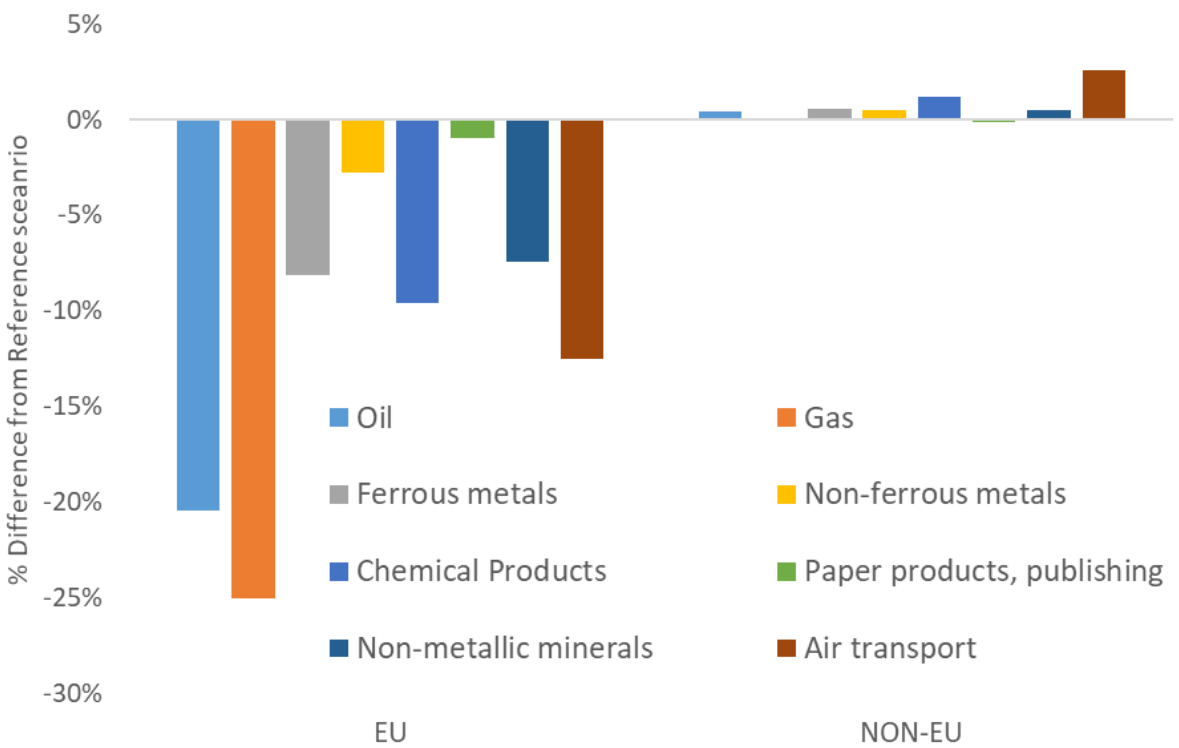

Figure 7. Cumulative changes in sectoral production in EUGD-Alone relative to the Reference scenario in EU and non-EU regions over 2025-2050.

Table 4. Impacts of EUGD_Alone on industrial production over 2025-2050.

\begin{tabular}{ccc}
\hline $\begin{array}{c}\text { Change from Reference over } \\
\text { 2025-2050 (in bn Euro 2010) }\end{array}$ & EU Production & Non-EU Production \\
\hline Oil & -3272 & 559 \\
Gas & -142 & 5 \\
Ferrous metals & -1103 & 795 \\
Non-ferrous metals & -251 & 419 \\
Chemicals & -2265 & 1803 \\
Paper and pulp, publishing & -153 & 63 \\
Non-metallic minerals & -1107 & 689 \\
Air transport & -1206 & 914 \\
\hline
\end{tabular}

Industrial leakage by sector is measured as the ratio of the amount of emission increases in non-abating countries over the amount of emissions reduced in countries pursuing climate action. The leakage rate is particularly high for energy-intensive industrial sectors, in particular for metals and chemicals, as a large part of the European production is relocated to non-abating regions, which have a considerably higher carbon intensity relative to the EU, as their energy mix is dominated by fossil fuels in the EUGD-Alone scenario. Industrial leakage rates as estimated by GEM-E3-FIT range from less than 5\% for non-energy intensive production up to $70-80 \%$ for chemicals and metals, which are highly exposed to foreign competition and are relocated to countries with considerably higher carbon intensity than the EU (e.g., China, India, Russia). A large share of increased emissions in non-regulating regions comes from power generation, due to the increased electricity demand from industries and their fossil-based power supply system; thus the imposition of emission reduction measures on electricity production in non-abating countries can significantly reduce leakage rates.

\subsection{Impacts of Joint EU-China Ambitious Climate Action}

When China and the EU jointly apply high carbon pricing, leakage is significantly reduced. The EU and Chinese cumulative GHG emissions are reduced by about $129 \mathrm{Gt}$ $\mathrm{CO}_{2}$ relative to Reference scenario over 2020-2050. In the same period, GHG emissions in non-abating regions increase by $7.7 \mathrm{Gt} \mathrm{CO}_{2}$ relative to Reference, indicating a carbon leakage rate of $6 \%$, mostly in India, Russia and the Rest of world regions (Figure 8). The 
leakage rate is substantially lower relative to EUGD_Alone scenario, as Chinese emissions are much higher than the EU's and about $85 \%$ of the overall mitigation effort in the EUGDChina scenario is implemented in China, with EU accounting for only $15 \%$. Therefore, a larger size of climate coalition would result in lower leakage rates. In addition, the imposition of common carbon price is more effective in abating emissions in countries with high carbon intensity, like China. Modelling outcomes suggest that carbon leakage can effectively decline in case that the climate coalition includes countries with high carbon intensity and with low industrial production costs, such as China.

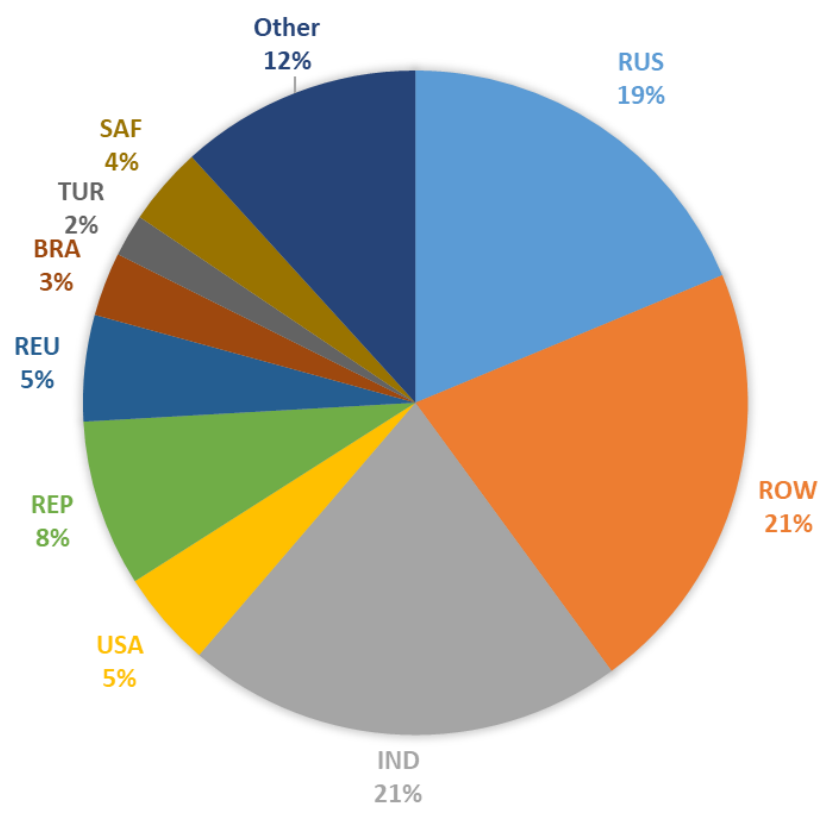

Figure 8. Leakage decomposition to regions in EUGD-China over 2020-2050.

The global demand for energy-intensive products (e.g., metals, cement) decreases in climate policy scenarios, due to the restructuring towards less carbon intensive products and services induced by carbon pricing. The higher relocation impacts are projected for the sectors producing metals and chemicals, due to their higher energy intensity and exposure to foreign competition.

Table 5 presents the EUGD-China scenario impacts on industrial activity with regulating countries experiencing activity losses in EITE industries relative to Reference. The losses are particularly high in the oil supply sector, but also in the production of metals and chemicals, as non-metallic minerals and paper are less traded. Part of the decreased activity in EU and China is relocated to non-regulating countries. The relative competitiveness and production shares in EITE industries of countries applying high carbon pricing change in the scenario. For example, the imposition of common carbon price would result in higher increase in Chinese production costs compared to EU, and thus the competitiveness of European EITE industries improves relative to Chinese industries. This means that energyintensive industrial production declines more strongly in China (Table 5) and the Chinese economy bears higher GDP losses than the EU. It should be noted that in EUGD-China scenario, the global industrial production is lower from Reference in all EITE sectors. The activity impacts are larger in China with its GDP declining by 1.6\% over 2020-2050 (with EU GDP declining by $0.7 \%$ ), due to the higher carbon intensity of the Chinese economy and the large-scale reduction of Chinese energy-intensive industrial production, as carbon pricing impacts more negatively the low-cost industrial producers like China. 
Table 5. Impacts of EUGD-China on industrial production over 2025-2050.

\begin{tabular}{cccc}
\hline $\begin{array}{c}\text { Production Change from } \\
\text { Reference over 2025-2050 } \\
\text { (in bn Euro 2010) }\end{array}$ & EU & China & Non-Abating Countries \\
\hline Oil & -2620 & -4642 & 701 \\
Gas & -115 & -30 & 14 \\
Ferrous metals & -290 & -4901 & 2710 \\
Non-ferrous metals & 52 & -1907 & 1155 \\
Chemicals & -1214 & -3558 & 2401 \\
Paper, publishing & -128 & -239 & 87 \\
Non-metallic minerals & -546 & -4282 & 1748 \\
Air transport & -794 & -122 & 580 \\
\hline
\end{tabular}

The relocation of manufacturing activities to non-abating countries leads to an increase in their energy and electricity consumption. As electricity trade across regions is limited, this would result in higher domestic production of electricity and higher $\mathrm{CO}_{2}$ emissions in non-abating countries, especially as their power generation mix is dominated by fossil fuels. The increased emissions from electricity production in non-abating countries are not related to changes in energy prices, but are a direct consequence of industrial relocation, through the competitiveness channel.

\subsection{How Effective Is the Border Carbon Adjustment?}

Policy makers explore measures to protect the competitiveness of EU energy-intensive industries, which are vulnerable to relocation away from the EU if it unilaterally adopts high carbon pricing. The EC considers the implementation of Border Carbon Adjustment (BCA) mechanism as part of the EU Green Deal. The main principles of a BCA are relatively well-defined and are already part of the current policy debate in the EU. The EUGDBCA scenario assumes that BCA is used to level the playing field between domestic and imported products with respect to carbon costs. With the right design, a BCA could prevent leakage, incentivise non-EU industries to shift toward lower emission technologies, and exert pressure on trade partners to strengthen environmental regulations. In the EUGDBCA scenario, the BCA is aligned with the EU ETS pricing, entailing a similar coverage of products and the requirement for importers to purchase carbon allowances at prices equal to the EU ETS. This policy instrument targets the carbon content of imported goods that fall under the EU ETS sectoral classification. The EU ETS carbon price is applied to imported goods from non-EU countries whose carbon intensity exceeds a certain threshold, which is proxied with the notion of Best Available Technology (BAT). The scenario does not assume direct participation of non-EU industries in the EU ETS, but the ETS carbon price is simulated as a tax, which is paid by economic operators at the point of entry in European borders. Essentially, the mechanism imposes an additional cost on non-EU goods based on the difference between the EU carbon intensity benchmark and the intensity of the sector and country of origin. The benchmark by sector is calculated using the technology with the lowest carbon intensity across EU Member States. The BCA revenues are recycled through the public budget, while no retaliation is assumed by non-EU countries. If non-EU countries apply the EU ETS carbon price on EU exports (retaliation), the effect on EU production would be relatively small as the EU industries already produce goods with low carbon contents implying limited impacts on their production costs.

As BCA captures the regional differences in carbon intensities and the cost increases induced by the ETS price, this instrument is very effective in mitigating carbon leakage, which declines from $25 \%$ in the EUGD-Alone to less than $4 \%$ (with the USA and China accounting for most of this leakage). The imposition of BCA increases the cost of imported industrial products in the EU, thus resulting in a reduction of EU imports by $1.5 \%$ cumulatively over 2025-2050 (Figure 9). However, this instrument is not designed to support the competitiveness of European industries in international markets, as exported goods do not receive any compensation for their higher production cost due to ETS carbon pricing, as a 
direct intervention would be non-WTO compliant. Therefore, GEM-E3-FIT results show limited impacts on European exports.

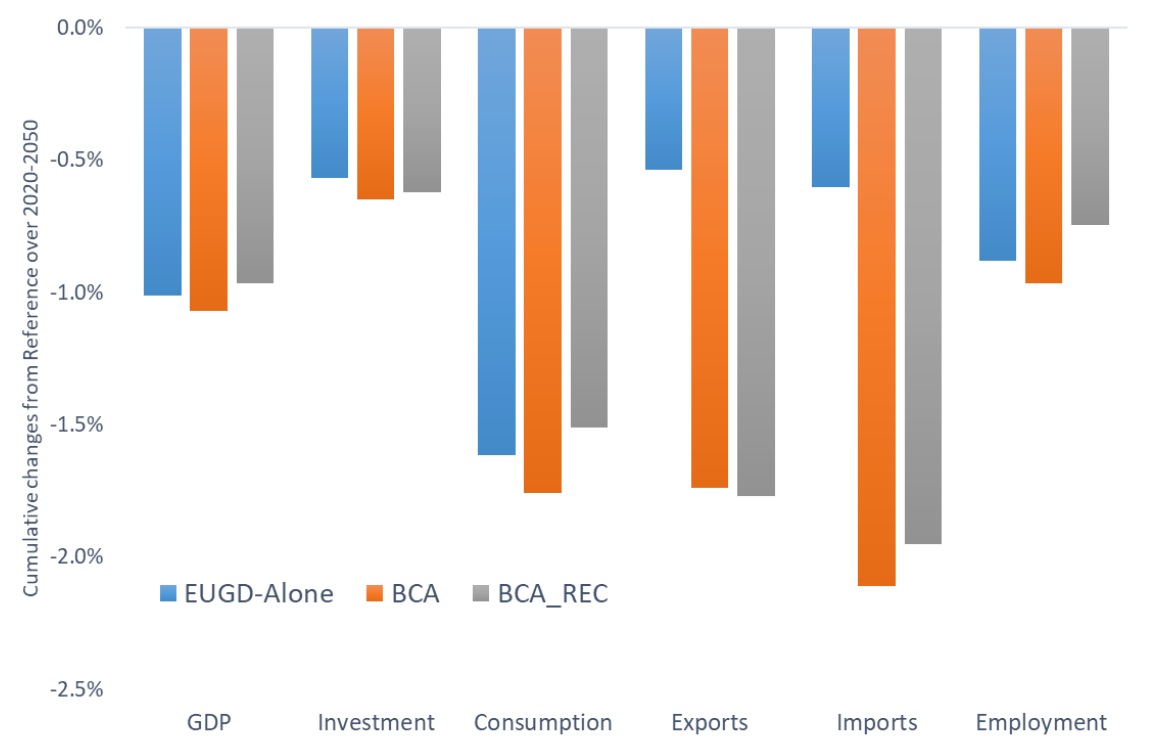

Figure 9. Macroeconomic impacts of alternative scenarios relative to Reference (cumulative changes over 2025-2050).

The recycling scheme used for the ETS and BCA revenues greatly affects the socioeconomic impacts of climate policies. If these revenues are recycled through the public budget, the implementation of BCA has a slightly negative impact on EU activity (with GDP declining by $0.06 \%$ over $2025-2050$ relative to EUGD-Alone); this is due to increased costs of imported products which is then diffused to domestic production and consumption through product value chains and complex inter-industrial relations. Additional taxes imposed on imported products further increase production costs of EU-based industries and reduce real disposable income for households. The negative impact on activity is found both in EU and non-EU countries as the tax imposition increases frictions in the economy.

The recycling of BCA revenues towards reducing social security contributions would reduce labour costs leading to the creation of additional jobs, with EU employment increasing by $0.3 \%$ relative to EUGD-BCA scenario. The increased labour income drives up private consumption and GDP, while also being beneficial for the EU trade balance. Our research shows that BCA is resilient to potential counteracting measures by non-EU competitors, as the low carbon intensity of EU products leaves little room for significant cost increases in its exported goods if a retaliation tax is applied.

The leakage-reduction effect of BCA is reflected in GHG emissions across regions, with global cumulative GHG emissions declining by $0.25 \%$ from EUGD-Alone scenario over 2025-2050. This means the same climate outcome and global emission budget can be achieved with lower ambition of domestic EU climate policies. The imposition of BCA results in reallocation of emissions among countries towards global cost-effectiveness, as global emissions decline, without impact on global GDP. However, BCA is only a secondbest instrument as emissions in non-regulating countries are still higher than their Reference levels and considerably higher relative to emission reduction pathways compatible with the Paris Agreement goals.

Unilateral emission pricing increases the risks of relocation for EITE industries, thus putting these industries at a disadvantage relative to international competitors [2]. The EU maintains a competitive position in the global production of energy-intensive products, despite losing market share over 2015-2050 in the Reference scenario due to increasing competition from rapidly growing developing economies. The EU-based manufacturing activity declines in the EUGD_Alone scenario, due to high carbon pricing, reduced domestic 
demand and lower international competitiveness. The EU share in global production of energy-intensive products declines by about 0.5 percentage point relative to Reference scenario. The imposition of BCA minimises the risks of industrial relocation to non-EU countries and thus European industrial production returns close to the Reference scenario levels. Metals, Chemicals and Non-metallic minerals have the highest sectoral performance in the BCA scenario because of their higher carbon intensity and share of EU imports compared to the other EU ETS sectors (Figure 10).

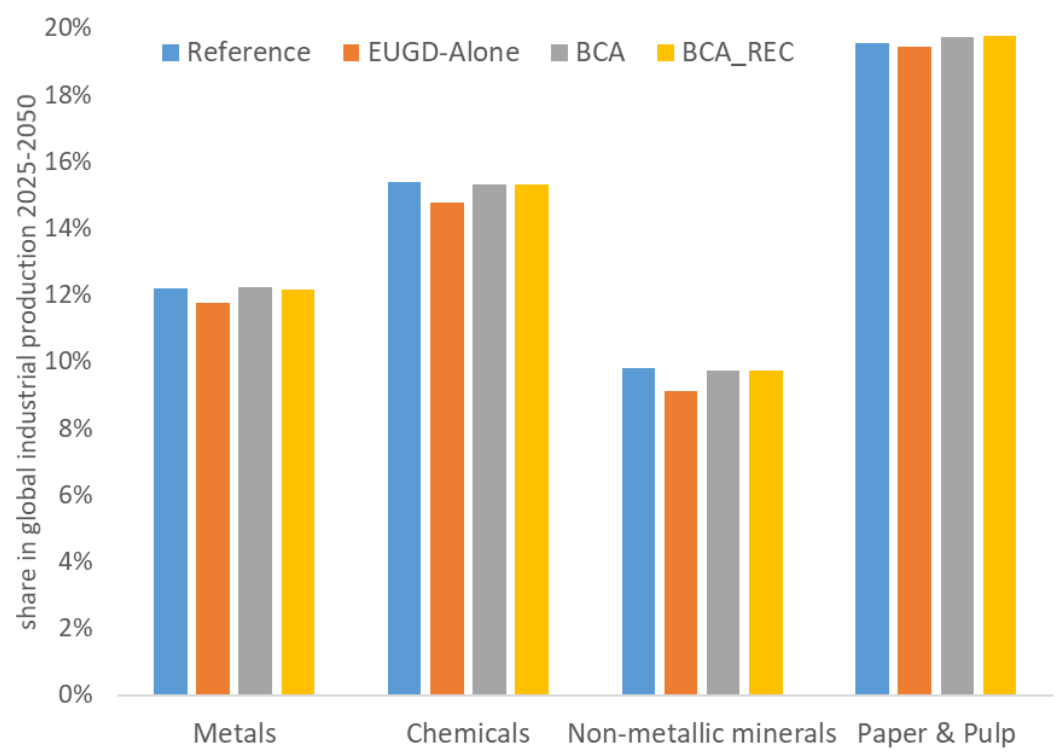

Figure 10. EU share in global industrial production in cumulative terms over 2025-2050.

\section{Policy Recommendations and Conclusions}

The ambition of European climate policies has increased in recent years, with the EC proposing to reduce EU GHG emissions by 55\% in 2030 relative to 1990 levels, paving the way towards climate neutrality by mid-century. Unilateral climate action increases the risk of carbon leakage, i.e., the relocation of GHG emissions to countries with weaker environmental regulation. Here, we evaluate the leakage induced by the industrial competitiveness channel, through shifts in comparative advantage and activity relocation of EITE industries. The enhanced version of GEM-E3-FIT model is used to analyse highly policy relevant scenarios based on the most recent climate debate, including the EU and China's pledges towards carbon neutrality by 2050 and 2060, respectively and the potential introduction of Border Carbon Adjustment mechanism aiming to minimize industrial relocation to non-abating countries.

Model-based outcomes show that without appropriate preventative measures, unilateral climate policies could induce relocation of energy-intensive activities outside the EU. The redistribution of trade in commodities between countries due to changes in their relative competitiveness leads to a carbon leakage of $25 \%$ over 2025-2050, induced by the increased emissions in non-abating countries, which is close to the higher end projected by the literature $[2,4,5,12,24]$. The carbon leakage computed with the GEM-E3-FIT model lies at the upper bound-but well within the range-of similar model results from the EMF29 multi-model study [2]. In the current study, we find a leakage rate for the EU at $25 \%$ whereas the mean of EMF29 models is around 20\%, but calculated in a limited horizon of 10 years and assuming less ambitious climate policies.

Most of the leakage occurs in China and India which have sufficient production capacities at low cost and relatively high energy and carbon intensities, inducing higher increase in emissions, while low transportation costs and proximity to the EU market favor Russia. The size and composition of countries participating in the climate coalition matters [25], as an EU-China coalition significantly reduces the leakage rate to about $6 \%$ 
over 2025-2050. This is due to the high effectiveness of carbon pricing to mitigate emissions in countries such as China, which have significantly higher carbon intensity and lower industrial production costs compared to the EU and other developed economies. The sectors producing metals and chemicals experience the highest leakage rates, because of their high energy intensity and foreign competition, while leakage in non-metallic minerals is smaller due to high transportation cost preventing activity relocation.

In case that EU and China join forces to reduce GHG emissions, the activity impacts are larger in the Chinese economy, as it has higher carbon intensity than the EU and bears about $85 \%$ of the overall mitigation effort. In this context, the cost competitiveness of European industries vis-à-vis the Chinese improves considerably, and thus EU industrial activity losses are very small. This indicates that linking the carbon markets of EU and China reduces more the competitiveness of China's energy-intensive activity in international markets compared to EU's. The adverse competitiveness impacts on the Chinese economy can be reduced in case that the allocation of mitigation effort is different (e.g., limited linking of EU and China carbon markets as in [26] or alternative sectoral distribution of effort as in $[27,28])$ or strengthened mitigation efforts are applied in other jurisdictions $[4,29,30]$. Our analysis suggests that China and the EU may establish a linked carbon market to further increase their emission reduction efforts, while at the same time taking preventative measures to effectively reduce the negative impacts of linking the two markets.

Recently, the BCA has been suggested in the EU Green Deal as a potential instrument to protect domestic industrial activities. The study aims to inform European and international policy makers on the socio-economic and industrial impacts of imposing BCA complementing domestic carbon pricing. As there are inherent difficulties in implementing rebates of emission payments on EU exports, we assume that BCA is implemented through tariffs on embodied emissions of products imported to the EU from non-regulating counties, in order to level the playing field between domestic and imported products in the EU with respect to carbon costs. We find that the imposition of a BCA mechanism can reduce leakage through the competitiveness channel and minimize the negative policy impacts on European EITE industries; therefore, BCA can effectively complement domestic carbon pricing. The adopted recycling scheme is highly important, as using $\mathrm{BCA}$ and emission revenues to reduce social security contributions is highly beneficial for domestic employment.

The model-based results crucially depend on the assumptions made, especially on the values of specific elasticities. The values of Armington elasticities capture the ease of substitution between domestically produced and imported goods in GEM-E3-FIT. High elasticity values imply that countries can easily substitute the sources for commodities leading to strong leakage through industrial relocation. A comprehensive sensitivity analysis on the values of these elasticities is required to consistently evaluate the emission and economic impacts of unilateral policies.

The study highlights that while a BCA can be effective in reducing leakage and industrial relocation, careful consideration should be given to its design with particular emphasis on how the revenues are used while ensuring compliance with WTO rules so as to limit retaliation from trading partners. Overall, the BCA brings clear benefits related to cost-effectiveness and domestic acceptance, but legal and administrative barriers may reduce the efficiency gains of $\mathrm{BCA}$, while its burden-shifting potential can be translated as a back-door trade policy against developing countries.

Author Contributions: Conceptualization, L.P. and P.F.; writing-original draft preparation P.F.; writing-review and editing, P.F. and K.F.; methodology, P.F., L.P. and K.F.; software, K.F.; validation, P.F., K.F., and L.P.; formal analysis, L.P. and P.F.; visualization, P.F. All authors have read and agreed to the published version of the manuscript.

Funding: The research leading to this study has received funding from the European Union Horizon 2020 research and innovation program under grant agreement No 730403 (INNOPATHS) and under grant agreement No 821124 (NAVIGATE). 
Institutional Review Board Statement: Not applicable.

Informed Consent Statement: Not applicable.

Data Availability Statement: The data presented in this study are available on request from the corresponding author.

Conflicts of Interest: The authors declare no conflict of interest

\section{Appendix A. GEM-E3-FIT Model Description}

GEM-E3-FIT is a large-scale multi-sectoral CGE model that since the 1990s has been extensively used by governments and public institutions to assess the socio-economic implications of policies, mostly in the domains of energy and the environment. The development of GEM-E3 involved a series of modelling innovations that enabled its departure from the constraining framework of standard CGE models (where all resources are assumed to be fully used) to a modelling system that features a more realistic representation of the complex economic system. The key innovations of the model relate to the explicit representation of the financial sector, semi-endogenous dynamics based on R\&D induced technical progress and knowledge spillovers, representation of multiple households, unemployment in the labour market and endogenous formation of labour skills. The model has detailed sectoral and geographical coverage, with 51 products and 46 countries/regions (global coverage), and is calibrated to a wide range of datasets consisting of Input-Output tables, financial accounting matrices, institutional transactions, energy balances, GHG inventories, bilateral trade matrices, investment matrices and household budget surveys. All countries in the model are linked through endogenous bilateral trade transactions identifying origin and destination. Particular focus is placed on the representation of the energy system where specialized bottom-up modules of the power generation, buildings and transport sectors have been developed. The model is recursive dynamic and produces projections of the economic and energy systems until 2100 in five-year time steps. The substitution elasticities of the model are derived from the general literature and are also econometrically estimated using the latest available datasets. The model is founded on rigorous and sound microeconomic theory allowing it to study in a consistent framework the inter-linkages of the economic sectors and to decompose the impacts of policies to their key driving factors. The model simulations are sensitive to a number of input parameters and modelling assumptions including capital costs of power producing technologies and associated learning rates, cost of capital and financing availability, easiness to substitute production factors, preferences over domestic and imported goods, etc. To address the uncertainty within, the model provides the option to make all its parameters stochastic according to user-defined probability distributions, and perform extensive sensitivity analysis.

The most important results provided by GEM-E3-FIT are: Full Input-Output tables for each country identified in the model, dynamic projections in constant values and deflators of national accounts by country, employment by economic activity and by skill and unemployment rates, capital, interest rates and investment by country and sector, private and public consumption, bilateral trade flows, consumption matrices by product and investment matrix by ownership branch, GHG emissions by country, sector and fuel and detailed energy system projections (energy demand by sector and fuel, power generation mix, deployment of transport technologies, energy efficiency improvements).

The representation of the financial sector in the GEM-E3-FIT model starts from the complete accounting of the financial flows-transactions among economic sectors. This accounting allows to determine the flow of funds, the debt profiles and the composition of agents' disposable income. The base year financial position of each agent is calculated using the institutional transactions statistics (full sequence of National Accounts that include all secondary transactions like property income, income from deposits, etc.) The net lending position of each agent is built from bottom-up data (all sources of income including dividend payments, interest rates, debt payments, bond interest rates, etc.) Data regarding the structure of the bilateral debt by agent are constructed according to current account statistics and proxies using cumulative bilateral trade transactions. All 
the financial transactions are arranged in a financial Social Accounting Matrix framework for each country that is represented in the model. From a modelling perspective, two additional economic sectors have been added (a world and a domestic bank) and six financial assets (deposits, time deposits, public bonds, corporate bonds, private loans and treasury bills). Banks collect savings from the economic agents in surplus and supply money at interest rates that clear the financial market (national or regional) while taking into account the risk premium and net credit position of each agent. The inclusion of the financial sector improves the simulation capabilities of the model in the following aspects:

(i) It moderates the short-term stress on capital markets by allocating capital requirements over a longer period (long-term financing schemes/loans). This effect is particularly visible in scenarios where the economy transits to a more capital-intensive structure and any limited availability of financing capital implies that capital costs will always rise.

(ii) It allows to simulate the role of carbon funds in implementation of ambitious climate policies.

(iii) It allows the assessment of socioeconomic impacts of investment projects characterized by different risk profiles performed by agents with different risk/debt profiles.

(iv) It allows for a detailed budgeting of debt by agent while it takes into account the impact of debt accumulation and debt sustainability in the ability of agents to borrow.

(v) Endogenous computation of interest rates for different financial assets (deposits, bonds, household and business financing, etc.) and direct link of nominal variables to the real economy.

(vi) Versatile financing options that correct market gaps (i.e., financing to low income households through energy-saving programs) and inclusion of financial repayment plans that allow to trace the interest payments in the future.

In GEM-E3, labour demand by firms depends on cost minimisation of their production function while labour supply is distinguished by skill and is modelled through an empirically estimated wage function (linking wages and labour supply) that allows for the existence of unemployment. The shift of labour demand to sectors requiring highly-skilled labour (i.e., a shift from agriculture to industrial manufacturing or financial services) can potentially cause a mismatch between demand and supply for specific skills and a potential skill shortage. The human capital module of GEM-E3-FIT allows households and firms to endogenously decide upon the optimal schooling-education years and on the optimal workforce training respectively. A household's decision to enter the labour market or acquire a skill (through additional education) depends on expected income (based on expectations on wages and unemployment rate by skill). The schooling decision of households concerns only certain age cohorts and allows to endogenously determine the participation rate and the supply of skills in the economy. The decision of firms to train their workers allows representing endogenous labour productivity growth through training.

In order to capture the "inequalities" within households that certain policies may imply, the new version of the GEM-E3-FIT model features for each country ten households that are distinguished by income class with different consumption patterns, different saving rates and sources of income according to the allocation of labour skills by type of household. This enhances the assessment of the social dimension of energy and climate policies enabling the assessment of income inequality within and across countries and the identification of vulnerable regions or agents. The inclusion of multiple households and human capital improves the simulation capabilities of the model by enabling the identification of potential bottlenecks due to skills scarcity and enabling productivity growth induced by R\&I and knowledge spillovers.

GEM-E3-FIT adopts a bottom up approach for the electricity sector representation with different power producing technologies. Electricity-producing technologies are treated as separate production sectors with discrete investment decision. Electricity-producing technologies have different cost structures and conversion efficiencies. Total generation costs are conceived in three categories: (i) investment costs, (ii) operating and maintenance costs and (iii) fuel costs (including also potential carbon costs). Unit cost data and future 
projections for investment and operating costs were extracted from the PRIMES database, while the fuel costs depend on other variables of GEM-E3-FIT. At the first nesting level of electricity sector, production is split into two aggregates, one consisting of a bundle of power-producing technologies (TECH) and the other represents the transmission and distribution part (DIST). There is a zero elasticity of substitution between these two aggregates. At the second level, all power-producing technologies included in GEM-E3-FIT are in the same nest, whereas the (DIST) bundle is disaggregated to capital, skilled and unskilled labour and materials. With regards to data reconciliation, the electricity sector in IO tables is split by unbundling power generation (by technology) from electricity transmission and distribution based on PRIMES base year data and future projections.

To further improve the modelling of electricity supply, a new bottom-up module for electricity production (GEM-E3-Power) has been developed, aiming to fully endogenise the investment and operation of the electricity system. GEM-E3-Power is a technologically rich partial equilibrium model describing the development of the electricity generation mix under alternative policy assumptions. The module is hard-linked with the core GEME3-FIT model, through iterative exchange of their common variables (e.g., technology shares, electricity demand and supply). GEM-E3-Power decides the optimal investment and operation of the electricity system in order to minimize the intertemporal total costs to produce electricity, including capital costs, Operation and Maintenance expenditures, carbon costs and costs to purchase fuels (as inputs to power plants), while meeting system constraints (e.g., demand, technology potentials, resource availability, policy constraints, system reliability and flexibility). Thirteen power generation options are included (coal, oil, gas and biomass-fired, nuclear, hydro, PV, wind onshore, wind offshore, geothermal, CCS coal, CCS gas and CCS biomass) and compete based on their Levelised Cost of Electricity (LCOE) to meet the electricity requirements. The decision to invest in power technologies depends on their relative cost, barriers and potentials, while various policy instruments can influence the future development of the electricity system, e.g., ETS carbon prices, phase-out policies, renewable subsidies or feed-in tariffs, standards, etc.

In GEM-E3-FIT modelling, both passenger and freight are included, while the choice of transport modes and technologies and the way of using transport equipment is extensively simulated. GEM-E3-FIT distinguishes between public and private mobility. Private mobility is part of derivation of consumption by purpose of households from utility maximization under the income constraint. In the nested optimization, mobility is split between using private transport means and purchasing services from transport suppliers (public transport). To use private transport, the optimization involves purchasing of durable goods (e.g., cars) depending on stock turnover considering the choice of car types with different capital and fuel consumption features. In particular, three types of private cars are included: conventional Internal Combustion Engine (ICE) cars, plug-in hybrid vehicles and battery electric cars. Each car type uses a different mix of fuels, with conventional ICE cars using diesel, gasoline, gas and biofuels, electric cars using electricity, and plug-in hybrids using electricity, oil products and biofuels. The model separates between transport activity that can be covered by the existing fleet of private cars considering the annual car scrapping rate and new registrations of private cars. Private consumption projections in the transport sector are endogenously derived with GEM-E3-FIT model. The shares of three car types $(r)$ in new car registration are calculated based on the Weibull discrete choice representation, as below:

$$
\operatorname{sshcar}_{r, t}=\frac{\operatorname{shcar}_{r, t} \cdot\left(\frac{p \operatorname{car}_{r, t}}{\text { pcar }_{r, t}}\right)^{s w w_{t}}}{\sum_{r} \operatorname{shcar}_{r, t} \cdot\left(\frac{p c a r_{r, t}}{\text { carr }_{r, t}}\right)^{s w_{t}}}
$$

where

$x_{s h c a r} r_{r, t}$ represents the share of car types in total new car registrations, shcar $_{r}$ is the scale parameter used for the calibration of technology shares, pcar $_{r, t}$ is the price by car type (reflecting total transport cost),

$s w_{t}$ is the elasticity of substitution between alternative car types. 
Mobility of private consumers is then translated into demand for specific car types, which in turn is related to demand for specific goods via the consumption matrix. The assumptions for fuel mix, technical efficiencies and other parameters (e.g., fuel use per passenger $\mathrm{km}$ ) are based on PRIMES data. In ambitious climate policy scenarios, the technology and fuel mix in transport modes changes endogenously as a result of carbon pricing and other instruments and changes in technology costs, while the fuel shares in households' consumption matrix (than links consumption by purpose to demand for specific goods) can be modified. The supply of professional transport is represented as production sectors distinguishing between land, air and maritime transport. Each transport sector produces a homogenous service using inputs from capital, labour, materials and energy, based on endogenous choice of firms towards cost minimisation. The demand of other production sectors for transport services derives from cost minimization of their production input mix. Substitutions are possible between transport modes and between transport and non-transport inputs depending on relative prices of goods and services.

\section{References}

1. Fragkos, P. Global Energy System Transformations to $1.5^{\circ} \mathrm{C}$ : The Impact of Revised Intergovernmental Panel on Climate Change Carbon Budgets. Energy Technol. 2020, 8, 2000395. [CrossRef]

2. Böhringer, C.; Balistreri, E.; Rutherford, T. The role of border carbon adjustment in unilateral climate policy: Overview of an Energy Modeling Forum study (EMF 29). Energy Econ. 2012, 34, S97-S110. [CrossRef]

3. Weyant, J.P. (Ed.) The Costs of the Kyoto Protocol: A Multi-Model Evaluation; The Energy Journal (Special Issue); Cleveland, OH, USA; pp. 1-398. Available online: https://web.stanford.edu/group/emf-research/docs/emf16/CostKyoto.pdf (accessed on 15 October 2020).

4. Paroussos, L.; Fragkos, P.; Capros, P.; Fragkiadakis, K. Assessment of carbon leakage through the industry channel: The EU perspective. Technol. Forecast. Soc. Chang. 2014, 90, 204-219. Available online: https://www.sciencedirect.com/science/article/ abs / pii/S0040162514000602 (accessed on 15 October 2020). [CrossRef]

5. Carbone, J.; Rivers, N. The Impacts of Unilateral Climate Policy on Competitiveness: Evidence from Computable General Equilibrium Models. Rev. Environ. Econ. Policy 2017, 11, 24-42. [CrossRef]

6. European Commission. Communication from the Commission to the European Parliament, the European Council, the Council, the European Economic and Social Committee and the Committee of the Regions. In The European Green Deal Brussels; COM 640 final; European Commission: Brussels, Belgium, 2019.

7. Hoel, M. Global Environmental Problems: The Effects of Unilateral Actions Taken by One Country. J. Environ. Econ. Manag. 1991, 20, 55-70. [CrossRef]

8. Böhringer, C.; Carbone, J.; Rutherford, T.F. Embodied Carbon Tariffs; NBER working paper; National Bureau of Economic Research: Cambridge, UK, 2011; p. 17376.

9. European Commission. State of the Union 2017-Industrial Policy Strategy: Investing in a Smart, Innovative and Sustainable Industry; European Commission: Brussels, Belgium, 2017.

10. Wesseling, J.H.; Lechtenböhmer, S.; Åhman, M.; Nilsson, L.J.; Worrell, E.; Coenen, L. The transition of energy intensive processing industries towards deep decarbonization: Characteristics and implications for future research. Renew. Sustain. Energy Rev. 2017, 79, 1303-1313. [CrossRef]

11. Aldy, J.; Pizer, E. The Competitiveness Impacts of Climate Change Mitigation Policie. J. Assoc. Environ. Resour. Econ. 2015, 2, 565-595. Available online: http:/ / www.nber.org/papers/w17705 (accessed on 15 October 2020).

12. DeCian, E.; Parrado, R.; Grubb, M.; Drummond, P.; Coindoz, L.; Mathy, S.; Stolyarova, E.; Georgiev, A.; Sniegoki, A.; Bukowski, M. A Review of Competitiveness, Carbon Leakage and EU Policy Options in the Post-Paris Landscape; Deliverable 3.1 of the COP21-RIPPLES H2020 project; European Commission: Brussels, Belgium, 2017.

13. Zachmann, G.; McWilliams, B. A European Carbon Border Tax: Much Pain, Little Gain; Policy Contribution 05/2020; Bruegel: Brussels, Belgium, 2020.

14. European Commission. Study on Energy Prices, Costs and Their Impact on Industry and Households; DG ENER.; European Commission: Brussels, Belgium, 2020.

15. Fragkiadakis, K.; Fragkos, P.; Paroussos, L. Low-Carbon R\&D Can Boost EU Growth and Competitiveness. Energies 2020, $13,5236$.

16. Fragkos, P.; Tasios, N.; Paroussos, L.; Capros, P.; Tsani, S. Energy system impacts and policy implications of the European Intended Nationally Determined Contribution and low-Carbon pathway to 2050. Energy Policy 2017, 100, 216-226. [CrossRef]

17. Capros, P.; Vita, D.A.; Tasios, N.; Siskos, P.; Kannavou, M.; Petropoulos, A.; Evangelopoulou, S.; Zampara, Z.; Papadopoulos, D.; Nakos, C.; et al. EU Reference Scenario 201-Energy, Transport. and GHG Emissions Trends to 2050; European Commission Directorate General for Energy, Directorate General for Climate Action and Directorate General for Mobility and Transport: Brussels, Belgium, 2016.

18. Armington, P.S. Theory of Demand for Products Distinguished by Place of Production. IMF Staff. Pap. 1969, 16, 159-178. [CrossRef] 
19. IEA. World Energy Outlook; International Energy Agency: Paris, France, 2019.

20. European Commission. Ageing Report; European Commission: Brussels, Belgium, 2018.

21. IRENA. Renewable Power Generation Costs in 2019; International Renewable Energy Agency: Abu Dhabi, UAE, 2020.

22. McCollum, D.L.; Zhou, W.; Bertram, C.; Boer, H.-S.d.; Bosetti, V.; Busch, S.; Després, J.; Drouet, L.; Emmerling, J.; Fay, M.; et al. Energy investment needs for fulfilling the Paris agreement and achieving the sustainable development goals. Nat. Energy 2018, 3 , 589-599. [CrossRef]

23. Cosbey, A.; Droege, S.; Fischer, C.; Reinaud, J.; Stephenson, J.; Weischer, L.; Wooders, P. A Guide for the Concerned: Guidance on the elaboration and implementation of border carbon adjustment. Int. Inst. Sustain. Dev. 2012, 2012, 22. [CrossRef]

24. Karkatsoulis, P.; Capros, P.; Fragkos, P.; Paroussos, L.; Tsani, S. First-Mover advantages of the European Union's climate change mitigation strategy. Int. J. Energy Res. 2016, 40, 814-830. [CrossRef]

25. Paroussos, L.; MANDEL, A.; Fragkiadakis, K.; Fragkos, P.; Hinkel, J.; Vrontisi, Z. Climate clubs and the macro-economic benefits of international cooperation on climate policy. Nat. Clim. Chang. 2019, 9, 542-546. [CrossRef]

26. Li, M.; Weng, Y.; Duan, M. Emissions, energy and economic impacts of linking China's national ETS with the EU ETS. Appl. Energy 2019, 235, 1235-1244. [CrossRef]

27. Alexeeva-Talebi, V.; Böhringer, C.; Löschel, A.; Voigt, S. The value added of sectoral disaggregation: Implications on competitive consequences of climate change policies. Energy Econ. 2012, 34 (Suppl. 2), S127-S142. [CrossRef]

28. Yumashev, A.; Ślusarczyk, B.; Kondrashev, S.; Mikhaylov, A. Global Indicators of Sustainable Development: Evaluation of the Influence of the Human Development Index on Consumption and Quality of Energy. Energies 2020, 13, 2768. [CrossRef]

29. Lisin, A. Prospects and Challenges of Energy Cooperation between Russia and South Korea. Int. J. Energy Econ. Policy 2020, 10, 130. [CrossRef]

30. Meynkhard, A. Long-Term prospects for the development energy complex of Russia. Int. J. Energy Econ. Policy 2020, 10, 224-232. [CrossRef] 